\title{
Do orixá ao mito: uma experiência em composição cênica
}

\author{
Grácia NAVARRO 1 \\ Universidade Estadual de Campinas - Unicamp
}

Neste artigo, descreverei uma forma de arquitetura cênica que desenvolvi a partir do princípio de equivalência, que estabeleci, entre o replicar de um leitmotiv no Candomblé e a "estrutura do mito", na visão de Claude Lévi-Strauss.

No Candomblé - religião brasileira, o contato com os deuses é intermediado pelo transe do iniciado. $\mathrm{O}$ iniciado em transe, corporificando um deus, apresenta uma dinâmica corporal que é replicada - no sentido de fazer copiado de uma matriz anterior, porém em materialidades heterogêneas: canto, toque de instrumentos, representação da divindade em transe, cores, aromas, sabores, saudações especiais que compõem a ação ritual pela dinâmica dos participantes em todo o espaço físico do terreiro. No entanto não se trata de um "replicar", em sequência, mas sim de um replicar simultâneo - que caracteriza particularmente o deus "em terra". Toda a performance do iniciado é construída de elementos da história mítica do deus incorporado, que por um processo de composição faz convergirem as ações da história do deus na construção de sua corporeidade - forma animada e dinamizada, poeticamente artificial e diferente das corporeidades humanas cotidianas.

Essa artificialidade carrega em si a desconstrução da identificação física entre os deuses e os seres humanos, que é feita pela plasticidade do corpo do iniciado em transe, a qual materializa o paradoxo entre divino e humano. Esse paradoxo, como entendido aqui, constitui o eixo central da tecedura dramatúrgica do ritual de incorporação. Esse paradoxo tem uma materialidade específica para cada Orixá, que chamarei de leitmotiv. Essa especificidade é composta pela convergência de significantes visuais, gestuais e sonoros, que são realizados simultaneamente na heterogeneidade das linguagens - Cênica: gestual do iniciado e do corpo coletivo; Musical: percussão, canto e saudações; Plástica: figurinos e objetos rituais; compondo a tecedura dramatúrgica da ação ritual.

\footnotetext{
${ }^{1}$ Doutora em Artes, docente do Instituto de Artes da UNICAMP. Seu trabalho é ativado no diálogo entre Dança e Teatro, Balé e Terreiro, Arte e Ciência. Diálogos transcriados em procedimentos técnicos e poéticos que aliam prática e reflexão, referências universais e regionais e experiência artística e didática. E-mail: gracianavarro@uol.com.br.
} 
Essa reflexão foi recriada em laboratórios de criação cênica, praticados ao longo de uma série de experiências. Nessas experiências cheguei a resultados que se repetiam e deram uma unidade ao conjunto de exercícios:

1. A instauração de um espaço-tempo inventado, no meio do espaço-tempo cotidiano, em oposição à evolução horizontal da estória com começo, meio e fim.

2. A comunicação entre o espetáculo e o público dá-se pela imersão do público na instauração do espetáculo, propondo a criação de um sentido que dispare da cena e se complete no espectador e além do tempo de contato entre o espectador e a cena.

3. Cena multifocal, com núcleos cênicos atuando simultaneamente, onde seguir um núcleo ou outro é um aspecto indiferente para compreensão da instauração.

No entanto, essa trajetória entre a referência e o resultado cênico/poético era muito vulnerável e o seu "fazer de novo" era um jogo entre o acesso a minha memória da última trajetória empreendida entre o estado bruto de um material e a síntese cênica. Um importante avanço foi feito quando estabeleci um princípio de equivalência entre o descrito replicar de um leitmotiv no Candomblé e a "estrutura do mito", na visão de Claude LéviStrauss, segundo o qual se constitui um método para a compreensão do pensamento mítico.

Agora, passemos então à estrutura do mito, seguindo a interpretação, que faço, da visão de Claude Lévi-Strauss, dando ênfase aos aspectos que interessam diretamente a esta pesquisa. A seguir retomarei a ideia sobre o princípio de equivalência que estabeleci entre o replicar de uma matriz anterior e a dita estrutura.

Para compreender o pensamento mítico é necessário entender a contradição como elemento fundador. Para um mito não é pedido coerência na sucessão dos fatos da sua narração.

Reconheçamos, antes, que o estudo dos mitos nos conduz a constatações contraditórias. Tudo pode acontecer num mito; parece que a sucessão dos acontecimentos não está aí sujeita a nenhuma regra de lógica e de continuidade. Qualquer sujeito pode ter um predicado qualquer; toda relação concebível é possível. Contudo, esses mitos, aparentemente arbitrários, se reproduzem com os mesmos caracteres e segundo os mesmos detalhes, nas diversas regiões do mundo. Donde o problema: se o conteúdo do mito é inteiramente contingente, como compreender que, de um canto a outro da terra, os mitos se pareçam tanto? (LÉVI STRAUSS, 1996, p. 240)

Segundo Lévi-Strauss, o mito está para a linguagem e também além dela. Ao aceitar que a linguagem se apresenta dividida em dois níveis diferentes: a língua e a palavra, os quais têm aspectos complementares, considera que a língua é estrutural e do domínio do 
tempo reversível e a palavra é do domínio do tempo irreversível e assim o é, também, o mito:

Um mito diz respeito, sempre, a acontecimentos passados: "antes da criação do mundo", ou "durante os primeiros tempos", em todo caso, "faz muito tempo". Mas o valor intrínseco atribuído ao mito provém de que estes acontecimentos, que decorreram supostamente em um momento do tempo, formam também uma estrutura permanente. Esta se relaciona simultaneamente ao passado, ao presente e ao futuro (Idem, ibidem).

O valor do mito como mito sobrevive a traduções, inclusive às ruins e é identificado como mito, mesmo que haja pouca informação sobre a língua e a cultura da população onde foi encontrado.

A substância do mito não se encontra nem no estilo, nem no modo de narração, nem na sintaxe, mas na história que é relatada. O mito é linguagem; mas uma linguagem que tem lugar em um nível muito elevado, e onde o sentido chega, se é lícito dizer, a decolar do fundo linguístico sobre o qual começou rolando. (Idem, p. 242)

O mito é distinto de qualquer forma de discurso, posto que seu significado não é assimilável nem aos fonemas, nem aos morfemas, nem aos semantemas, situando-se no nível da oração e conformando grandes unidades constitutivas nomeadas mitemas. Os mitemas seguem os princípios que servem de base à análise estrutural como um todo: "economia de explicação; unidade de solução; possibilidade de reconstituir o conjunto a partir de um fragmento e de prever os desenvolvimentos ulteriores a partir dos dados atuais" (Idem, p. 243).

Esses mitemas foram transcritos em cartões que eram numerados correspondendo ao seu lugar na sucessão dos fatos da narrativa, quando: "Percebe-se, então, que cada cartão consiste na atribuição de um predicado a um sujeito. Ou melhor, cada grande unidade constitutiva tem a natureza de uma relação" (Idem, ibidem).

Esta organização dos cartões corresponde ao desenvolvimento horizontal da narrativa do mito, corresponde, apenas, ao domínio do tempo não reversível. No entanto, o caráter específico da dupla natureza do tempo mítico - ao mesmo tempo reversível e irreversível, sincrônica e diacrônica, encontrará correspondência quando os cartões são organizados em feixes de relações, seguindo a suposição de que as unidades constitutivas do mito não são as relações isoladas e que seu significado só é compreendido sob a forma de combinação desses feixes.

A leitura do mito dá-se assim como a leitura de uma partitura musical de orquestra: 
....uma partitura de orquestra não tem sentido se não for lida diacronicamente segundo um eixo (página após página da esquerda para a direita), mas ao mesmo tempo, sincronicamente, segundo o outro eixo, de cima para baixo. Ou seja todas as notas situadas na mesma linha vertical formam uma grande unidade constitutiva, um feixe de relações (Idem, p. 244).

Para ilustrar diretamente o método, Claude Lévi-Strauss usará o mito do Édipo. Esse mito será ordenado em uma sequência que contempla a ordem diacrônica e sincrônica, indissociáveis para a compreensão do mito.

\begin{tabular}{|c|c|c|c|}
\hline \multicolumn{4}{|l|}{$\begin{array}{l}\text { Cadmo procura sua irmã } \\
\text { Europa, raptada por Zeus }\end{array}$} \\
\hline & & Cadmo mata o dragão & \\
\hline & $\begin{array}{l}\text { Os Spartoi se exterminam } \\
\text { mutuamente }\end{array}$ & & \\
\hline & & & $\begin{array}{l}\text { Lábdaco (pai de Laio) = } \\
\text { "coxo" (?) }\end{array}$ \\
\hline & Édipo mata seu pai Laio & & $\begin{array}{l}\text { Laio (pai de Édipo) = } \\
\text { "torto" (?) }\end{array}$ \\
\hline & & Édipo imola a Esfinge & \\
\hline & & & Édipo = "pé inchado" (?) \\
\hline \multicolumn{4}{|l|}{ Édipo esposa Jocasta } \\
\hline & $\begin{array}{l}\text { Etéocles mata seu irmão } \\
\text { Polinice }\end{array}$ & & \\
\hline $\begin{array}{l}\text { Antígone enterra Polinice, } \\
\text { seu irmão, violando a } \\
\text { interdição }\end{array}$ & & & \\
\hline
\end{tabular}

A hipótese da tabela é de que cada uma das colunas agrupa relações que evidenciam um traço comum: a primeira coluna à esquerda corresponde a parentes consanguíneos com um grau de intimidade que excede as regras sociais - relações de parentesco superestimadas. A segunda coluna corresponde a parentes consanguíneos, assim como a primeira, mas apresentada pelo inverso: relações de parentesco subestimadas ou depreciadas. A terceira coluna corresponde aos monstros tectônicos vencidos. A quarta coluna, os três nomes têm caráter comum e evocam uma dificuldade no andar.

A interpretação do mito do Édipo, no caso deste artigo, é dispensada, posto que para a ilustração do problema condizente com este projeto basta a condição das relações em feixe serem a estrutura das relações sincrônicas entre estes eixos como produtoras do significado do mito.

A estrutura até aqui descrita foi transcriada como estrutura do exercício cênico. A seguir descreverei como se opera este trânsito da estrutura do mito para a estrutura da cena. 
Para tanto, parto da experiência do Exercício número 07, em uma ação simultânea de rever e atualizar procedimentos usados em exercícios anteriores. Desse exercício participaram 25 alunos/atores, cursando a disciplina Folclore Brasileiro: Dança, onde eu desenvolvo o estudo das danças brasileiras na dinâmica de um processo criativo.

Numa primeira etapa, foi trabalhada a constituição de uma "cultura comum" ao grupo. Esta abarcava códigos de atuação, corporeidade, desenho da ação cênica e a relação com o imaginário como síntese de autoria entre o ator e o material em pesquisa. Todo esse material constituiu o referencial técnico comum a todos.

A esse referencial técnico comum foi agregado um referencial temático, que, para esse exercício, selecionamos o candomblé, a capoeira e rituais fúnebres populares.

Uma série de improvisações foram realizadas desdobradas de uma história dada, na qual os fatos sucediam-se assim: enquanto se preparava a mortalha de um cidadão, sua vida era rememorada e correspondia a uma relação com o candomblé e com a capoeira. O cidadão morre em uma roda de capoeira.

Analisando as improvisações sobre as múltiplas narrativas desdobradas da história, é possível definir os estados/instaurações que a compõem. Concluí que estávamos fazendo quatro estados/instaurações: 1. Candomblé; 2. Vida; 3. Combate; 4. Morte.

Por "instauração" entendo uma ação cênica com mais de um foco de atenção, no entanto, tratando de maneiras diferentes, um mesmo tema.

Após um primeiro período de improvisação, os atores foram divididos em núcleos de atuação. Entendo por núcleos de atuação os pequenos grupos que vão agir entre si formando cenas sobre o tema de cada instauração. O conjunto das cenas concebidas por cada núcleo foi o motivo da nomeação de cada um: As moiras (núcleo 1), Os capoeiristas (núcleo 2), As namoradas (núcleo 3), As iniciadas (núcleo 4). Para cada estado/instauração cada um dos núcleos construiu um elemento que confluía para as instaurações propostas. A composição de cada núcleo, que articulada compunha a instauração integral, foi desdobrada da cultura comum do grupo tanto para a ação cênica quanto para as referências temáticas: candomblé e capoeira.

A seguir apresentarei uma tabela com imagens das cenas de cada núcleo em cada uma das Instaurações:

\begin{tabular}{|l|l|l|l|l|}
\hline $\begin{array}{l}\text { NÚCLEOS } \\
\text { DE } \\
\text { ATUAÇÃO }\end{array}$ & INSTAURAÇÃO & INSTAURAÇÃO & INSTAURAÇÃO & INSTAURAÇ̃̃O \\
\hline & $\begin{array}{l}\text { CANDOMBLÉ } \\
\text { (instauração 1*) }\end{array}$ & $\begin{array}{l}\text { VIDA } \\
\text { (instauração 2) }\end{array}$ & $\begin{array}{l}\text { COMBATE } \\
\text { (instauração 3) }\end{array}$ & $\begin{array}{l}\text { MORTE } \\
\text { (instauração 4) }\end{array}$ \\
\hline
\end{tabular}




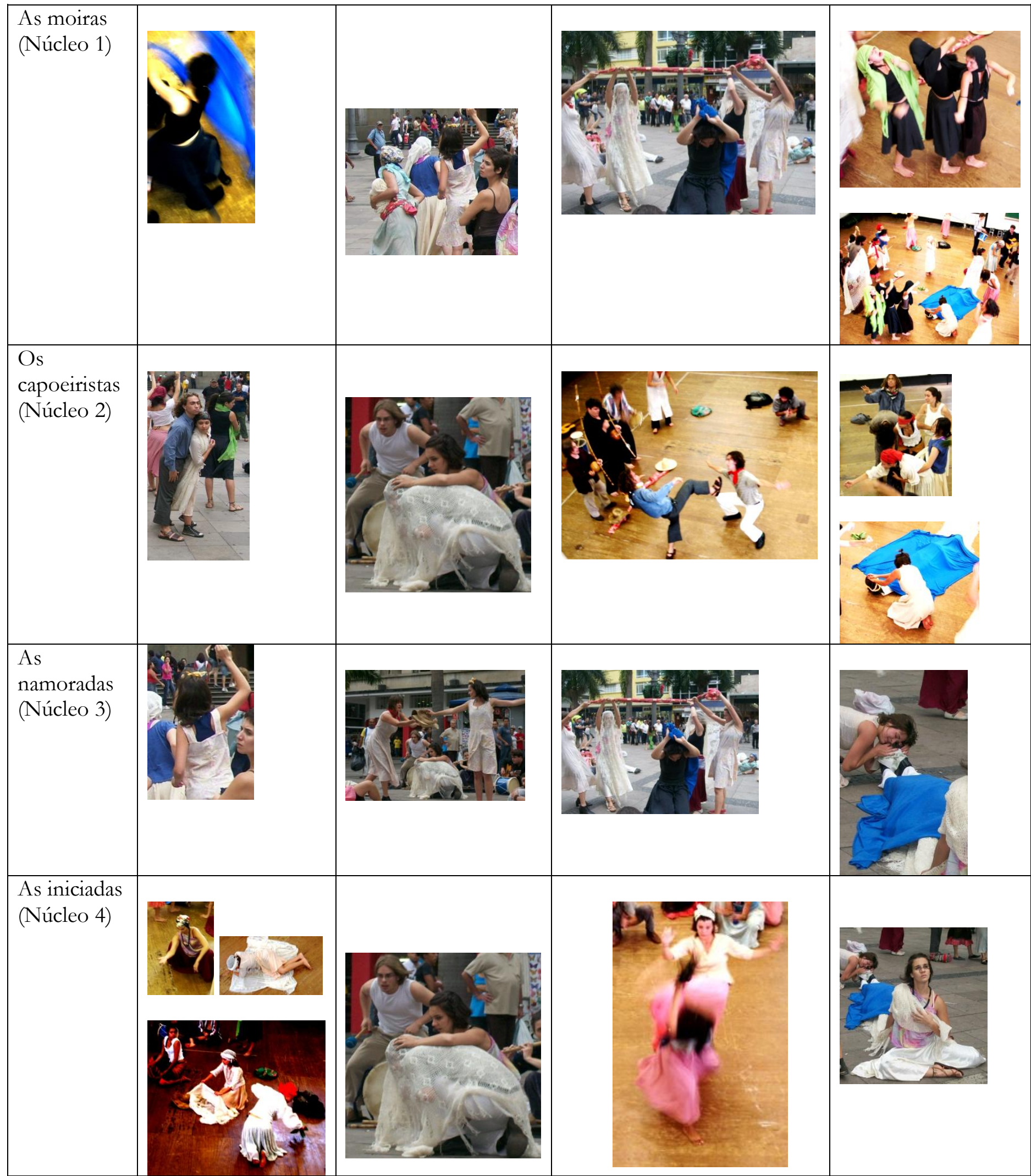


Para cada instauração cada núcleo deve expressar a relação que tem com o tema da instauração. Por exemplo: na instauração "candomblé”, o núcleo dos capoeiristas expressa sua relação com o candomblé; na instauração "vida", esse núcleo expressa sua relação com "vida", e assim, desta mesma maneira, para as outras instaurações.

As sequências de instaurações estabelecem a linha horizontal e diacrônica da ficção. Cada instauração é feita de um conjunto de ações realizadas pelos atores organizados nos núcleos de atuação, assim como está exposto na tabela:

\begin{tabular}{|l|l|l|}
\hline \multirow{3}{*}{ Ficção } & Instauração (1) & Núcleo 1 \\
& & Núcleo 2 \\
& Núcleo 3 \\
\cline { 3 - 3 } & Núcleo 4 \\
\cline { 2 - 3 } & Instauração (2) & (idem) \\
\cline { 2 - 3 } & Instauração (3) & (idem) \\
\cline { 2 - 3 } & Instauração (4) & (idem) \\
\hline
\end{tabular}

Cada instauração é uma unidade da encenação, composta pela versão dada simultânea e articuladamente pelos seis núcleos atuantes. A esta sequência de instaurações dei o nome de ficção, no sentido de história inventada, em oposição à história comprovada na vida real. A sucessão das instaurações propõe uma leitura diacrônica da história e a atuação simultânea dos núcleos, na sucessão das instaurações, propõe uma leitura sincrônica e multifocal da peça. Sendo assim, é possível ter uma leitura diacrônica da peça, marcada pela sucessão das instaurações e comum a todos os espectadores que a assistirem do começo ao final e, também, é dado ao espectador a possibilidade de uma segunda camada de leitura, quando ao seguir ora um núcleo, ora outro, em ação no curso das instaurações, poderá ter versões diferentes sobre relações com o candomblé, a vida, o combate e a morte.

Com a exposição e análise da transcriação da estrutura do mito para a estrutura da cena, buscou-se a articulação da singularidade de cada ator num tecido narrativo coletivo.

Esse formato proporcionou uma conexão com o fazer teatral contemporâneo ao enfatizar a singularidade do ator, o caráter único de acontecimento da apresentação e a situação de não representação. 


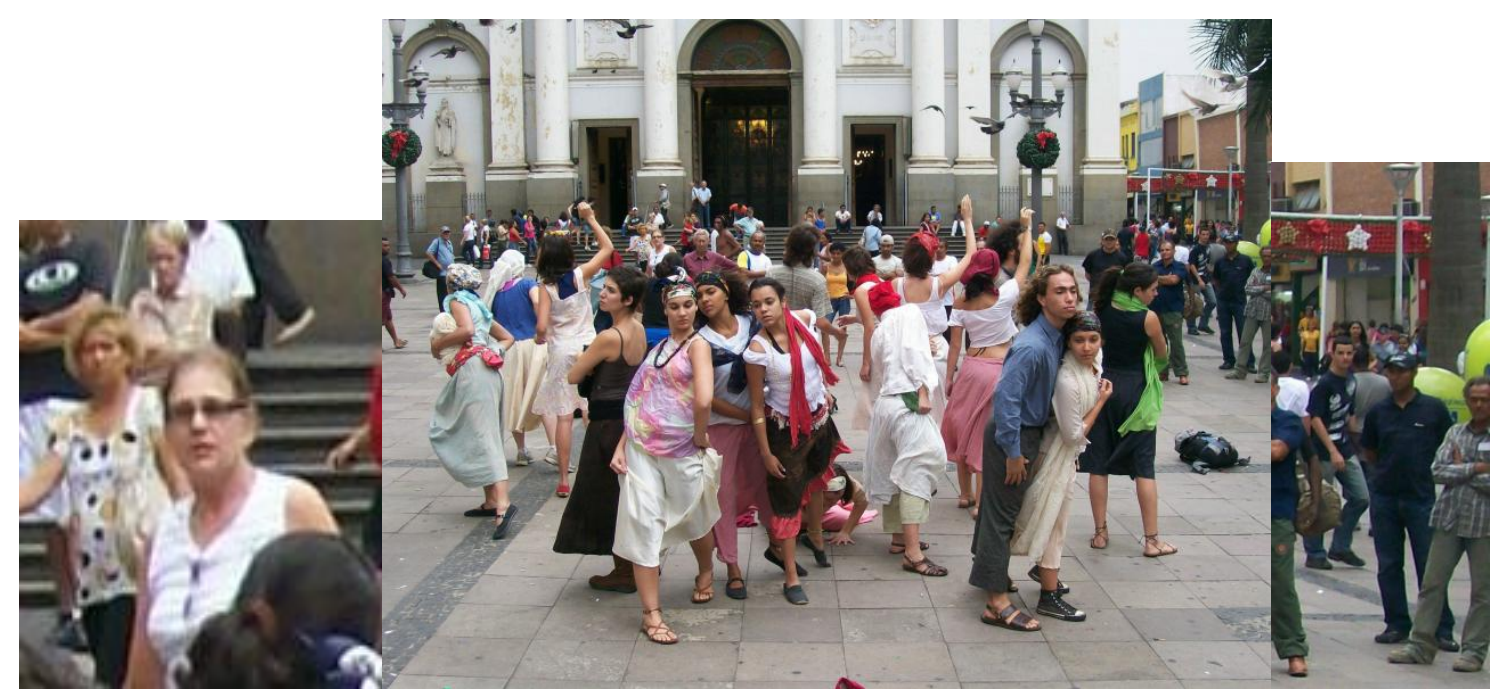

Esse exercício cênico foi realizado, também, no centro de Campinas em dezembro de 2007- SP.

Foto: Priscila Paes.

BIBLIOGRAFIA CITADA:

LÉVI-STRAUSS, Claude. Antropologia estrutural. Rio de Janeiro, Tempo Brasileiro, 1996.

Abstract: This research shows a synthesis of scenic creative process that emerges from a particular way of approaching in the construction of ritual action in the Candomble and the Structure of Myth by Claude Lévi-Strauss.

Keywords: creative process; theater; myth. 